\title{
The Intersection of National Security and Climate Change
}

\author{
Informing Decision Makers
}

A Symposium Hosted by

The Henry M. Jackson Foundation and

Pacific Northwest National Laboratory (PNNL)

\author{
June 4, 2014
}

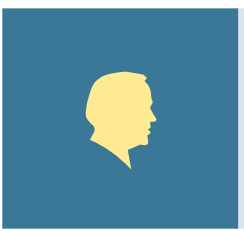

H E N R Y M. J A C K S O N

$\begin{array}{llllllllll}\text { F } & \text { O } & \text { U } & \text { N } & \text { D } & \text { A } & \text { T } & \text { I } & \text { O } & \text { N }\end{array}$

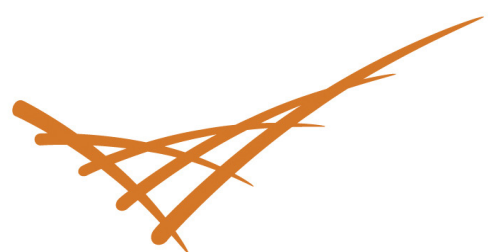

Pacific Northwest

NATIONAL LABORATORY 


\title{
The Intersection of \\ National Security and Climate Change
}

\author{
Informing Decision Makers
}

\section{An Urgent Call to Action'}

In his May commencement speech to newly commissioned second lieutenants at West Point's graduation, President Obama warned that climate change is "a creeping national security crisis that will help shape your time in uniform." Climate change poses significant risks to national security, homeland security, and human security. In the coming decades, these young officers, civilian leaders, and decision makers nationwide will need to make choices about protecting their populations and assets from harm.

Decision makers must face a number of issues that are impacted by climate change, such as where to station troops or how to respond best to humanitarian crises. These concerns have clear national security impacts. Other climate-related issues, such as the manage-

Climate change is "a creeping national security crisis that will help shape your time in uniform."

\section{- President} Obama ment of climate refugees or the appropriate development of low-lying areas, may not have such obvious national security implications. Yet the national security repercussions from these issues can be significant.

On June 4, 2014, the Henry M. Jackson Foundation and the Pacific Northwest National Laboratory hosted a groundbreaking symposium in Seattle, Washington, that brought together 36 leaders from federal agencies, state and local governments, NGOs, business, and academia. The participants examined approaches and tools to help decision makers make informed choices about the climate and security risks they face. The following executive summary is based on the day's discussions and examines the problem of climate change and its impact on national security, the responses to date, and future considerations. Throughout the day there were many suggestions for next steps and actions needed. 


\section{Assessing the Problem}

\section{The Effects of Climate Change Can Be Felt Now}

Participants agreed that climate change is beyond doubt and drew particular attention to two climate-related reports. First, the National Climate Assessment ${ }^{2}$ represents the consensus opinions of 300 leading scientists in the United States. The report found that the effects of human-induced climate change are already being felt throughout the country. It says, "While scientists continue to refine projections of the future, observations unequivocally show that climate is changing and that the warming of the past 50 years is primarily due to human-induced emissions of heat-trapping gasses."

Second, a recent report from CNA's Military Advisory Board ${ }^{3}$, a group of retired military leaders, echoed these sentiments, finding that climate change is no longer a future threat-it is happening now. The CNA report also stated, "The nature and pace of observed climate change-and an emerging scientific consensus on their projected consequences-pose severe risks for national security."

\section{Climate Change Has Broad Impacts on National Security}

Understanding the complex relationship between climate change and national security will be a key challenge for analysts and decision makers. One participant emphasized that national security not only involves protecting citizens from an outside armed attack but also consists of guarding citizens from a variety of climate-induced threats.

Issues such as water scarcity, food prices, resource distribution, refugees and over-migration, and maritime boundary disputes will affect national security. Internationally, climate change impacts are already accelerating instability and conflict in volatile regions and adding tension even to stable regions. The military and government will face increasing requests for humanitarian assistance, disaster relief, and wildfire management. At the local level, governments must support military bases and ensure that service roads, electric grids, and communication lines are stable and operational in climate emergencies. Creating strategic plans for local, regional, and national governments will accelerate rapid and effective response to climate-based national security concerns.

Simple cause-and-effect models do not accurately describe the climate-security nexus. However, participants concluded that climate impacts (rising sea levels, tropical cyclones, floods, droughts, riverine erosion) create human security impacts (freshwater access, food production, infrastructure destruction, disease outbreak, migration), which in turn lead to state security impacts (conflict and increased stress on weak governments). 


\section{A Key Domestic Example: Hampton Roads}

Hampton Roads, Virginia, provides a clear example of the national security threat posed by a changing climate. There are 29 military facilities in the area, including the only facility that builds aircraft carriers and the company that builds half of America's submarine fleet. Rising sea levels are placing this infrastructure at risk of flooding. While the facilities are under federal control, the State of Virginia holds responsibility for the civil infrastructure and roadways. Even if the Department of Defense can protect the bases, keeping Hampton Roads operational will require coordination between different levels of government to ensure that military personnel can reach the facilities and have electricity available once they arrive.

\section{A Key International Example: The Arctic}

Participants focused on the increasing effects of climate change on the Arctic. With up to six weeks of open water expected in 2025, governments and industry are rushing into the Arctic to capture natural resources and shorten cargo transportation times. An Arctic passage from China to Europe can save several days versus a trip through the Suez Canal. Increased usage of the Arctic may lead to greater opportunities for new conflict.

\section{Responses To Date}

\section{Government, Military, and Business Leaders React}

Participants offered a mixed assessment on the status of climate change politics. There was considerable pessimism on the national prospects for legislation and about the likelihood of congressional action on climate, despite the urgency with which many politicians view the issue. On the other hand, many local and regional governments, as well as other government agencies at the federal level, have taken more decisive steps forward.

Climate

change used

to be a dirty word. Now the question is at what level to fund climate efforts.
Looking more broadly at the U.S. government, and specifically regarding major federal agencies and the military, participants reported that at the highest levels of leadership there is a growing understanding of the need to tackle climate change and the threat it poses to national security. According to one participant, "Climate change used to be a dirty word. Now the question is at what level to fund climate efforts." Military views of the matter are also evolving, particularly when senior decision makers are committed to addressing the issue.

Domestically, the federal government is taking steps to protect critical infrastructure impacted by climate change. For example, the U.S.

Army Corps of Engineers reviews infrastructure such as levees, dams, roads, and public works to strengthen those at greatest risk. Water management is a significant challenge due to sea level rise 
and increased flooding.

Abroad, the U.S. increasingly will conduct operations to stabilize regions under duress from climate-related problems. Extreme climate events such as sustained drought or salt-water intrusion into low-lying agricultural lands can ruin crops, cause over-migration, and lead to social unrest.

One participant stated that while major military deployments are unlikely, the military will position small forces in many locations to respond to the new threats. To achieve progress in stabilizing regions, participants emphasized that a multi-level government approach is required to improve security and provide key services, such as effective governance, food, healthcare, and water.

The political dynamics playing out across the federal government are similar to those faced by industry. At one major company with Pacific Northwest operations, corporate leaders have varying levels of commitment to addressing climate change. However, all business leaders respond to climate challenges when they are seen to pose risks to corporate health. Emphasizing the risk to the business bottom line elevates attention to the issue even in corporate boardrooms.

One specific suggestion emerged during this discussion: the creation of a national flood standard. While building standards are set at the state level, the federal government could define a flood standard for all federal investments, including cases like Hampton Roads. The government's buying power could help encourage this standard across the marketplace.

\section{Pacific Northwest Provides a National Model for Action}

Many communities in the Pacific Northwest are serious about addressing climate change and national security threats. Climate scientists have reported that the Northwest region of the country will likely experience increasing wildfires from decreased snowpack, increasing storms leading to flooding, and rapid ocean acidification.

These changes pose numerous economic and safety challenges, such as alterations of salmon spawning patterns and increased risks of rockslides that threaten both infrastructure and human life. Furthermore, sea level rise also places critical infrastructure such as railroads and ports at risk due to their low elevation. Federal, state, and regional governments will be forced to deploy resources and manpower to respond.

Local governments are using these findings in future planning. For example, the bipartisan King County Council, which covers the greater Seattle region, called for the development of a strategic climate action plan. The groundbreaking plan provides a blueprint for carbon mitigation and adaptation that could be used as a national model for other localities.

Utilities in the region are also planning for impacts, including the ability to serve military bases. The City of Bellingham, Washington, a community close to the Canadian border, is redeveloping its waterfront but faces risks from rising seas. To preserve its investments, the city has planned land 
usage to avoid placing long-term, critical structures in areas that are likely to flood in coming decades. Similarly, the City of Anacortes, a community on Puget Sound, recognized that its drinking water supply was at risk from flooding based on future climate modeling. To address this risk, a recent two-year project involved tasks such as elevating electrical switch gear to protect Anacortes' water treatment plant against a 100-year flood. Cities that plan strategically in this manner will be better positioned to confront severe climate effects and reduce demands on the federal government and military.

\section{Looking Ahead}

\section{Effective Communication Strategy Is Critical}

Throughout the day, discussion repeatedly focused on how to better communicate the risks caused by climate change and why action is imperative. Communication tactics must build public awareness, inform policy makers, and engage larger-scale entities like local and regional government agencies and the business community.

Communicating with the public. Engaging the public is a critical component of ensuring the success of climate policy. Nationally, polarized attitudes about climate change require different messaging depending on the audience and the region of the country. Some attendees recommended enhancing the message using compelling personal stories, as well as by focusing on specific climate and national security impacts like food and water scarcity.

Outreach to policy makers. The complexity of sharing scientific data and technical modeling further complicates the message, including in outreach to policy makers. Several participants raised the importance of translating those scientific findings to actionable items and comprehensible policy for politicians. Highly localized data will be the most useful in encouraging action and planning. Informing a member of Congress that his or her district may be at risk of flooding or drought and that a military installation is threatened will make a more compelling argument.

Modeling, particularly on the local level, can play a role in influencing plans, though the scientific precision necessary to support this decision-making does not exist today. One participant said, "We need to be able to translate the broad global climate models to the regional and the local level. Decision makers need to know what this means for them."

Military leaders and their increasing emphasis on the national security risks of climate change may well influence and persuade policy makers otherwise resistant to messaging from environmental and even economic organizations. As an example, the military's high operational need for energy requires more convoys of fuel and water. More convoys through con- 
tested areas mean the potential loss of personnel. The military is consequently working to develop alternative fuels. Establishing the connection, therefore, between alternative fuel development and national security could be an important tool to gain congressional support.

\section{Interaction with government agencies and business groups.}

Rhetoric matters. Participants raised the challenge of framing the climate-national security issue clearly for a wide variety of government and business related entities. A major corporation needs to understand that these concerns transcend environmental issues and impact bottom-line corporate profits. One participant noted that while the phrase "climate change" did not gain traction, "preparing for climate extremes" did. On the other hand, government at all levels must be persuaded that potential impacts encompass politics, economics, population, migration, and health as well as climate and environment. Connecting climate change effects to national security will be a powerful tool to convey that message.

Suggested approaches included:

- Use visualization tools like simple graphics, video of submerging land, or digital photos to give people immediate and localized information, for example to help a homeowner to decide whether to rebuild after a natural disaster.

- Emphasize negative economic impacts that are immediate and individual, rather than focusing on vague warnings involving future generations.

- Choose apolitical words, such as "extreme weather events" rather than "climate change."

- Highlight actions taken by the military to give credibility to the urgency of the issue.

\section{Efforts Needed on Both Mitigation and Adaptation}

A number of attendees emphasized the need for a balance between mitigation and adaptation.

Regarding mitigation, one participant said that absent substantial reductions in emissions, there will be severe and widespread impacts on unique and threatened systems, compromised human activity, and the extinction of a large fraction of species. Another remarked that mitigation actions are imperative in addressing global warming. Mitigation suggestions included increasing the costs of fossil fuels while reducing costs of alternative energies and putting costs on carbon emissions. Technologies include refining carbon capture and storage techniques and developing clean coal production.

Some of the discussion on adaptation included the military's growing appetite for alternative fuels. The military is the country's largest single user of oil in the U.S., which drives its interest in developing alternatives to fossil fuels. According to the CNA report, "By reducing our dependence on a single fuel source, such as fossil fuels, these efforts make our bases more operationally resilient and our fighting forces more effective." 
Participants called for additional research into technologies that make the country more prepared. Technologies may also be developed for use internationally to aid other nations as they respond to climate change effects.

Several attendees mentioned the difficulty of decision making and planning given the existing level of uncertainty about emission reduction. Models must account for the possibility of different outcomes depending upon emission levels, which results in ranges. It was stressed that past trends are important in planning but fail to take into account more severe changes expected in the future. Participants agreed on the need for more science and research to gain precision in modeling and to reduce uncertainty.

Reflecting on technology that will aid adaptation, participants noted the use of satellite imagery and unmanned aerial vehicles that could help improve situational awareness for first responders by alerting them to downed power lines or blocked roads. Modeling human responses was also seen as essential to preparing response plans. Understanding likely outcomes in advance can inform resource prioritization decisions. As an example, it was mentioned that more focused research is needed on the effect of climate migration and population shifts due to extreme weather events (such as after Hurricane Katrina) and how these can impact other urban centers.

\section{Comprehensive Action Plan and Leadership Urgently Needed}

Participants broadly agreed that greater, coordinated efforts are essential. Regional partnershipssuch as the Pacific Coast Collaborative and international efforts such as the U.S. dialogue with Pacific Rim countries - are vital. Within our own nation, there needs to be coordination between local, state, and federal governments regarding all climate-based impacts, particularly in responding to emergencies. The military has significant experience working on these issues that could be shared with other organizations.

Several participants called for a strategy to guide action. Addressing the

Regional partnerships-such

as the Pacific Coast Collaborative and international efforts such as the U.S. dialogue with Pacific Rim countriesare vital. similarities between climate change today and cybersecurity ten years ago, one person suggested that decision makers develop a framework to address the adaptation side, similar to cyber security. Companies are investing in cyber security because they are losing money on the issue. There needs to be a similar case made regarding climate change.

Climate change is complex. Efforts to influence public opinion on climate change pose political risks, yet politicians need to make tough choices on climate and security. Policy-savvy scientists and policy makers who understand science have to ensure that important information is not lost in translation. Scientists also have to educate the public with actionable knowledge that is appropriate for the scale of the decisions that are required.

Congress thus far has not acted on climate change. To break this impasse, Congress needs to hear from a variety of interested groups and 
engaged citizens. Members of Congress will care about the issue when they hear about it from concerned voters, including their business constituencies. One participant emphasized, "We have to invite business to this conversation." Another stressed the importance of communicating with major energy companies and groups such as local chambers of commerce.

Ultimately, securing the homeland is a shared responsibility of all of society: government, the private sector, advocacy organizations, and academia. The tent of stakeholders is broad and the message must be clear. Climate change is real and it will impact our national security. Urgent action is critical and requires a bipartisan effort in order to succeed. As one participant summarized, "We can't give up. We have to act. And it can start in the Northwest."

\section{Footnotes}

1. The symposium was conducted under the Chatham House Rule. The views represented in this summary are the participants' own and do not necessarily reflect their organizations or the views of the Henry M. Jackson Foundation, Pacific Northwest National Laboratory, or the U.S. Department of Energy.

2. See more at http://nca2014.globalchange.gov/report

3. See CNA's report, National Security and the Accelerating Risks of Climate Change at http://www.cna.org/reports/ accelerating-risks\#sthash.S4sqQGF0.dpuf

The Henry M Jackson Foundation was founded in 1983 to continue the unfinished work of the late Senator Henry M. "Scoop" Jackson in the areas in which he played a key leadership role: international affairs education, human rights, environment and natural resources management, and public service. Through its grant making and strategic initiatives, the Foundation seeks to make a lasting impact and perpetuate the Jackson legacy for the benefit of future generations.

Interdisciplinary teams at Pacific Northwest National Laboratory address many of America's most pressing issues in energy, the environment, and national security through advances in basic and applied science. Founded in 1965, PNNL employs 4,300 staff and has an annual budget of about $\$ 950$ million. It is managed by Battelle for the U.S. Department of Energy. 